\title{
AS FINANÇAS NA PERCEPÇÃO DE ESTUDANTES DE ENGENHARIA DE PRODUÇÃO: UM ESTUDO DE CASO
}

\author{
Heloisa dos Santos Zampieri (UFPR) zampieriheloisa@gmail.com \\ Ruth Margareth Hofmann (UFPR) ruthofmann@gmail.com
}

\section{Resumo}

Este trabalho apresenta os resultados de uma pesquisa acerca da percepção de estudantes de engenharia de produção sobre a área financeira. Para isso, foram aplicados questionários compostos por questões relativas ao perfil do discente, suas motivações para o aprendizado sobre mercado financeiro, a importância atribuída às competências do engenheiro de produção e o seu conhecimento sobre finanças. As análises foram embasadas pela bibliografia referente à formação em engenharia de produção, bem como por estudos que relacionaram o engenheiro de produção e o setor econômico. Dentre os resultados, foi possível identificar que os acadêmicos do presente estudo revelam interesse em finanças para investimento pessoal e atuação profissional. Por outro lado, os estudantes indicaram ter conhecimento superficial de temas financeiros específicos, ainda que tenham reconhecido a relevância de competências de gestão econômica para atuação em Engenharia de Produção.

Palavras-Chaves: Mercado financeiro, Ensino em Engenharia, Gestão Econômica.

\section{Introdução}

O mercado financeiro no Brasil vem passado por um processo de expansão pautado pelo avanço do mercado de capitais e pela elevação da rentabilidade das instituições financeiras (BACEN, 2019). Tal expansão não se dá apenas mediante ampliação da quantidade de investidores no mercado de ações, tendo reflexo, inclusive, no aumento da demanda por profissionais qualificados para atuar na gestão financeira. Dentre os requisitos para a atuação em finanças podem-se destacar competências e habilidades analíticas somadas às competências e habilidades quantitativas.

Diferentes cursos de graduação em Engenharia no Brasil proporcionam a formação de profissionais qualificados para a gestão financeira. Os salários relativamente mais elevados no 
mercado financeiro, aliados ao perfil de formação em Engenharia, tem feito com que engenheiros tenham preterido áreas como a indústria e a construção civil. Vieira (2013) descreve o processo de migração de engenheiros para o mercado financeiro a partir das vantagens da área financeira em relação aos requisitos para atuação na construção civil, por exemplo.

A Engenharia de Produção, em particular, visa à formação de profissionais com bagagem robusta de competências gerenciais, incluindo a gestão financeira. Esse perfil, delineado no âmbito da Engenharia, têm motivado bancos, corretoras e seguradoras a preferirem Engenheiros de Produção em detrimento de profissionais formados em áreas as ciências sociais aplicadas (MEDEIROS, 2018). É nesse contexto que o presente artigo apresenta os resultados de uma pesquisa acerca da percepção de estudantes de engenharia de produção sobre a área financeira. Para isso, foram aplicados questionários compostos por questões relativas ao perfil do discente, suas motivações para o aprendizado sobre mercado financeiro, a importância atribuída às competências do engenheiro de produção e o seu conhecimento sobre finanças.

A pesquisa foi realizada com estudantes da Universidade Federal do Paraná (UFPR) entre janeiro e fevereiro de 2020. Cabe mencionar que a estrutura curricular do curso conta com 3 disciplinas obrigatórias mais diretamente vinculadas relacionada a gestão financeira, sendo: economia, engenharia econômica e contabilidade de custos industriais. Para a construção dos questionários foram utilizadas a certificação Profissional ANBIMA, série 10 (CPA-10), devido ao fato de que profissionais atuantes neste âmbito possuem obrigatoriedade legal da certificação, assim como as competências do engenheiro de produção (ABEPRO).

O artigo conta com 4 seções além desta introdução. A seção 2 apresenta a revisão de literatura. A seção 3 expõe os procedimentos metodológicos adotados. A seção 4 apresenta os resultados obtidos, cabendo à última seção as considerações finais do trabalho.

\section{Revisão da literatura}

O sistema financeiro, a economia real e o sistema produtivo são influenciados diretamente pelos fluxos financeiros, esses, que por sua vez, possuem movimentos dinâmicos e mutáveis. O engenheiro de produção, por possuir habilidades gerenciais precisa entender os movimentos dos fluxos financeiros nacionais e internacionais para planejar tomadas de ações nas atividades econômicas e de processo produtivo, além de poder prever riscos e antecipar 
oportunidades para as empresas. Ademais, o conhecimento destes profissionais na área de economia e finanças deve estar sempre atualizado (PINHEIRO, 2001). Note-se que a evolução do sistema financeiro se faz acompanhar da maior disponibilidade e complexidade de instrumentos financeiros, o que exige o acompanhamento contínuo das mudanças no universo dos investimentos.

Em trabalho recente, Martins e Donadone (2017) tiveram como foco de pesquisa estudantes de engenharia de produção da Universidade Federal de São Carlos (SP) nos últimos períodos da graduação e seus primeiros postos de trabalho após conclusão do curso. O estudo justificou a escolha do engenheiro de produção devido à sua preferência por cargos de controle. Assim, a pesquisa acompanhou os egressos que almejavam cargos na área de finanças e pôde concluir que o engenheiro de produção passou a fazer o papel do antigo economista.

Como motivação da atuação do engenheiro neste âmbito profissional, Khalil (2018) identifica em pesquisa como o perfil do graduando em engenharia se adequa ao setor financeiro. A justificativa para tal tendência é de que o acadêmico de engenharia apresenta uma percepção dos fatos pela sensação e não pela intuição, ou seja, necessita dos fatos e figuras para uma tomada de decisão. Khalil (2018) exemplifica que para lançar um produto este grupo faria uma pesquisa de mercado ao invés de utilizar a intuição, isto é, a ação desenvolve-se por meio do racional e por este motivo se adequa às exigências do setor financeiro.

Corroborando a aptidão e necessidade do mercado econômico financeiro pelo engenheiro de produção, a formação deste profissional tem por base a resolução CNE/CES 11, publicada em 11 de março de 2002 e o documento de diretriz curricular da Associação Brasileira de Engenharia de produção. O primeiro documento diz respeito à formação geral das engenharias no Brasil, enquanto o segundo é referente à composição das competências a serem desenvolvidas na instrução do engenheiro de produção. Dentre as 10 competências requeridas pela ABEPRO está: "utilizar indicadores de desempenho, sistemas de custeio, bem como avaliar a viabilidade econômica e financeira de projetos” e, dentre as áreas e subáreas praticáveis está "Gestão econômica”.

Demonstrando a importância da oferta de disciplinas no setor econômico financeiro pela Universidade que oferece a graduação em engenharia de produção, além das exigências da ABEPRO, a pesquisa de Coutinho e Santos (2016) ressalta a relevância deste contato no conhecimento do discente. O levantamento de dados e informações dos autores indica que o nível de compreensão do acadêmico após cursar a disciplina de matemática financeira, no curso de engenharia de produção na cidade de São Paulo, elevou-se e permitiu que os alunos 
mobilizassem conceitos básicos da educação financeira em práticas da gestão do seu próprio dinheiro. Mesmo com o progresso descrito, Coutinho e Santos (2016), apontam a importância da instituição de ensino incluir um maior conteúdo de educação financeira, visto que os alunos demonstraram possuir conhecimento superficial em investimentos financeiros, mesmo que haja a possibilidade e provável necessidade de transpor tais conhecimentos para a esfera pessoal e empresarial.

Em complementação dos objetos de aprendizagem da área econômica e como forma primária conhecimento em produtos financeiros e investimentos, Khalil (2019) ressalta que a certificação ANBIMA série 10 tem o intuito de padronizar práticas e garantir a confiabilidade dos mercados financeiro e de capitais, elevando a capacitação técnica do profissional (ANBIMA, 2019). Para atuar profissionalmente no mercado financeiro a certificação é necessária. Visando, então, à qualificação dos indivíduos que exercem ou pretendem exercer tais profissões, a ANBIMA (2019) inclui os principais temas do CPA 10: Sistema Financeiro Nacional; Ética, Regulamentação e Análise do Perfil do Investidor; Noções de Economia e Finanças; Princípios de Investimento; Fundos de Investimento; Instrumentos de Renda Variável e Renda Fixa; e Previdência Complementar Aberta (PGBL e VGBL).

\section{Metodologia}

O presente trabalho se caracteriza como estudo de caso (SILVA e MENEZES, 2005) estruturado como uma abordagem quanti-qualitativa. Tendo partido da revisão de literatura, foi construído um formulário online para ser respondido por estudantes de Engenharia de Produção da Universidade Federal do Paraná (UFPR). Para o cálculo amostral do total de acadêmicos integrantes da pesquisa foi considerado o número de matrículas ativas do $3^{\circ}, 5^{\circ}, 7^{\circ}$ e $9^{\circ}$ período. Deste modo a população consistiu em 256 estudantes.

Com a população conhecida, o tamanho da amostra foi calculado conforme indicado na equação:

$$
\begin{gathered}
n_{0} \frac{1}{E_{0}^{2}} \\
n=\frac{n_{0} \cdot N}{N+n_{0}}
\end{gathered}
$$

Sendo: 
n: Primeira aproximação do tamanho da amostra

$\mathrm{E}_{0}$ :Erro amostral, estabelecido em $10 \% \mathrm{n}$ - tamanho da amostra

$\mathrm{N}$ : tamanho da população

O tamanho da amostra ideal foi então calculado como sendo de 71 acadêmicos de engenharia de produção da UFPR. Devido ao critério de resposta voluntária e disponibilidade dos participantes, a amostra final contou com 65 discentes. Cabe notar que a pesquisa foi realizada durante as férias dos estudantes, o que pode ter afetado a quantidade de repostas obtidas.

O questionário sobre o estudo de engenharia de produção da Universidade Federal do Paraná e o setor financeiro apresentava como objetivo principal identificar qual é o interesse do aluno de engenharia de produção em relação ao setor econômico financeiro e expor, em paralelo, qual é o nível de conhecimento que possuem sobre o assunto. Complementarmente, o questionário buscou identificar o grau de importância que os alunos atribuem às diretrizes da ABEPRO sobre as competências, áreas e subáreas do engenheiro de produção.

O questionário em questão foi aplicado via formulário online, divulgado por meio de e-mails e redes sociais. Foram realizadas 10 perguntas. Dentre as questões, 4 buscavam identificar o perfil do entrevistado, 2 possuíam o propósito de reconhecer a importâncias das diretrizes da ABEPRO e, por fim, 4 tiveram a finalidade de reconhecer o interesse e conhecimento dos alunos sobre o setor econômico financeiro. É fundamental evidenciar que as questões de análise de importância e conhecimento foram feitas em escala Linkert.

\section{Resultados}

A partir das respostas obtidas, os resultados são apresentados em 4 eixos: perfil do acadêmico; atribuição de importância às diretrizes da ABEPRO; interesse no setor financeiro; e conhecimentos sobre modalidades específicas de investimento.

\subsection{Perfil do acadêmico}

A partir do questionário foi possível identificar o perfil dos acadêmicos de engenharia de produção (UFPR) que participaram da pesquisa. O resultado demonstra que $89,3 \%$ dos entrevistados já cursaram a disciplina de Economia - inserida no $3^{\circ}$ período da graduação enquanto 43,1\% também cursaram Engenharia Econômica - inserida no $7^{\circ}$ período. No que se refere à atuação profissional (gráfico 2), mais de $50 \%$ da amostra está inserida no mercado de trabalho, sendo como estagiário, efetivado ou empreendedor em sua própria empresa. 
Gráfico 1 - Período do Acadêmico Gráfico 2- Inserção no mercado de trabalho
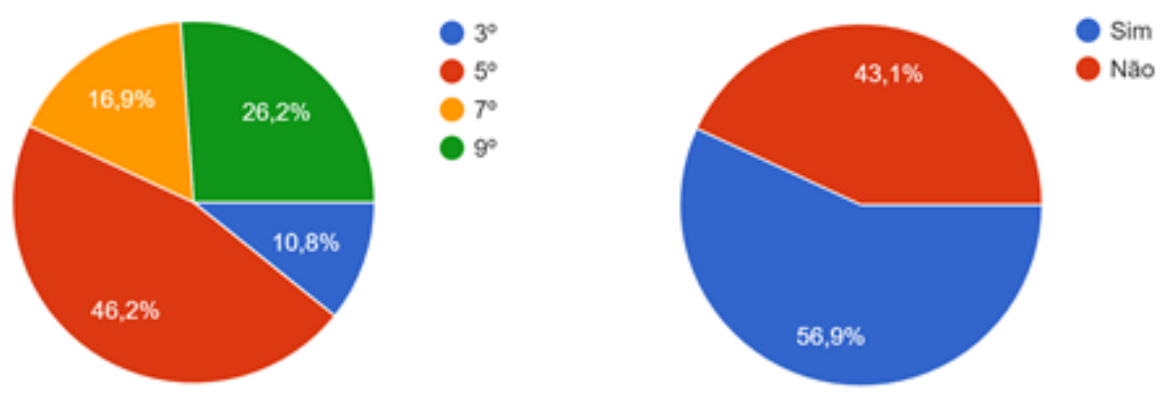

Fonte: Elaboração própria (2020)

Em paralelo, observa-se que grande parte dos estudantes já superaram metade do curso, o que favorece a confiabilidade dos resultados, uma vez que há um maior entendimento sobre as competências necessárias para a sua formação e aplicação no mercado de trabalho.

\subsection{Critério de importância das diretrizes da ABEPRO}

A segunda parte do questionário teve o intuito de identificar a relevância atribuída pelos estudantes às competências e subáreas que a ABEPRO exige do engenheiro de produção. o gráfico 3 apresentada a pergunta: "Quão importante você considera a seguinte Competência do Engenheiro de Produção: 'utilizar indicadores de desempenho, sistemas de custeio, bem como avaliar a viabilidade econômica e financeira de projetos"”. O questionamento em questão faz referência à nona competência da diretriz da ABEPRO, e, de acordo com as respostas obtidas os alunos consideram esta habilidade como "importante" ou "muito importante".

Gráfico 3 - Importância da $9^{\circ}$ Competência do Engenheiro de Produção (ABREPRO) 


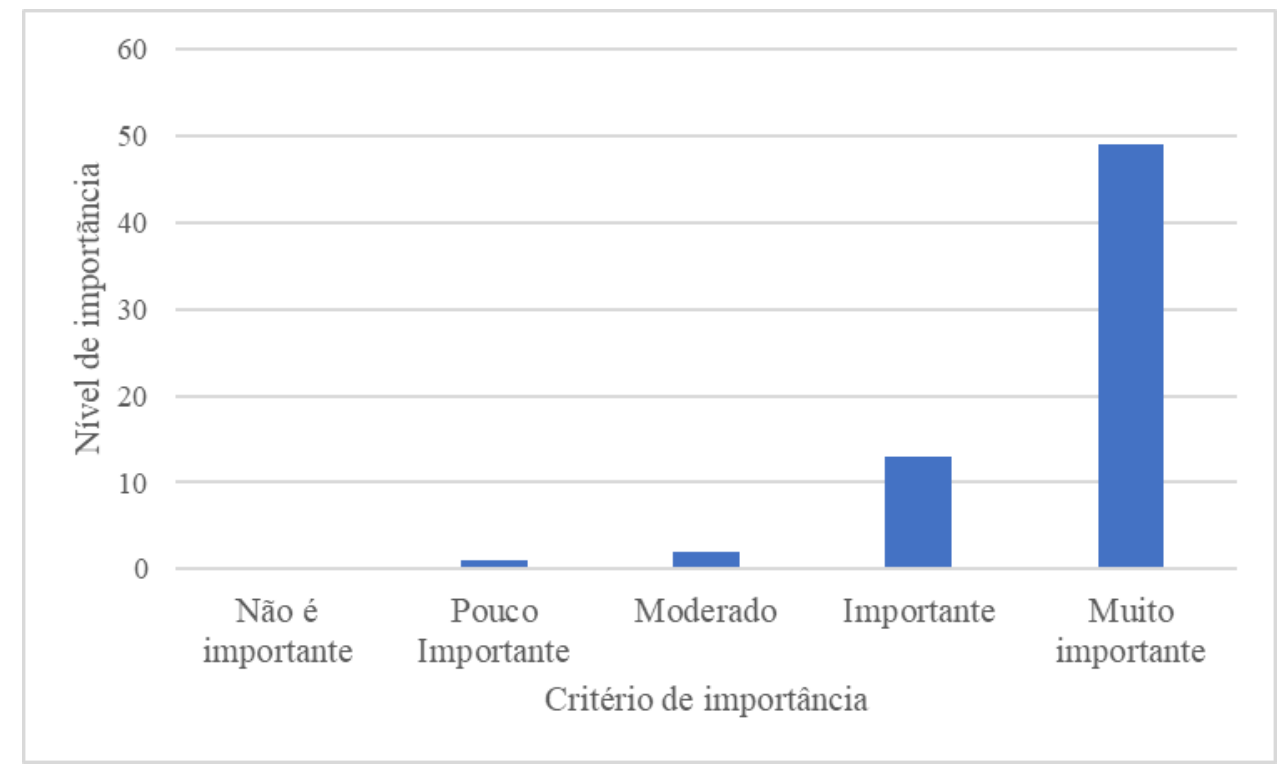

Fonte: Elaboração própria (2020)

Em sequência, os estudantes foram questionados sobre com quais subáreas de engenharia de produção eles mais se identificavam ou consideravam importante. $\mathrm{O}$ resultado do gráfico 4 indica que 36 alunos apresentam afinidade ou muita afinidade com a Sub - área de "Gestão Econômica", o que demonstra a relevância de matérias atreladas a esse assunto dentro da grade de engenharia de produção na Universidade Federal do Paraná.

Gráfico 4 - Importância das Competência do Engenheiro de Produção (ABREPRO)

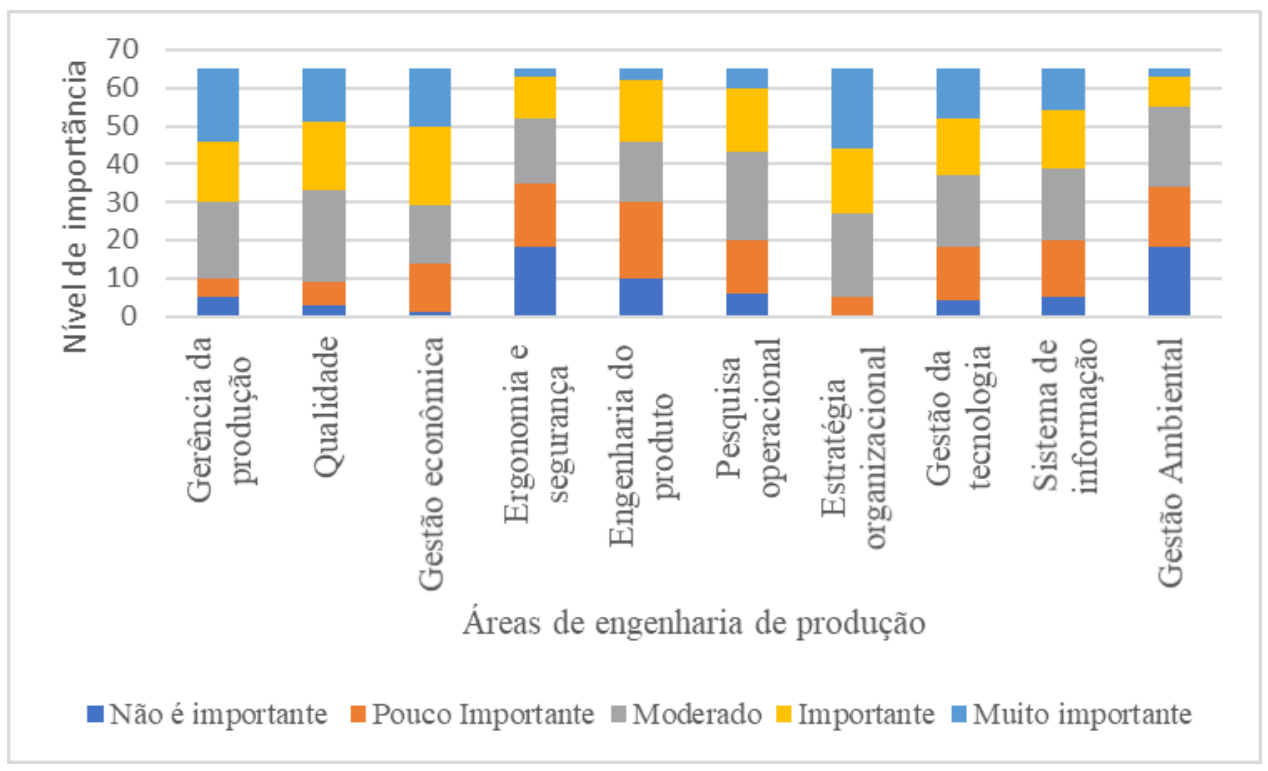

Fonte: Elaboração própria (2020) 
Note-se que, quando se considera a quantidade relativa de estudantes que declararam afinidade com gestão econômica, são 54\% do total da amostra.

\subsection{Interesse no setor financeiro}

Para compreender o real interesse do acadêmico no setor financeiro, além do seu olhar direcionado à graduação, os estudantes foram questionados sobre o potencial de aplicação de conhecimentos financeiros - podendo selecionar "investimento pessoal" e "atuar como profissional" simultaneamente ou exclusivamente para cada uma das 3 alternativas (gráfico $5)$.

Gráfico 5 - Interesse do acadêmico no setor financeiro

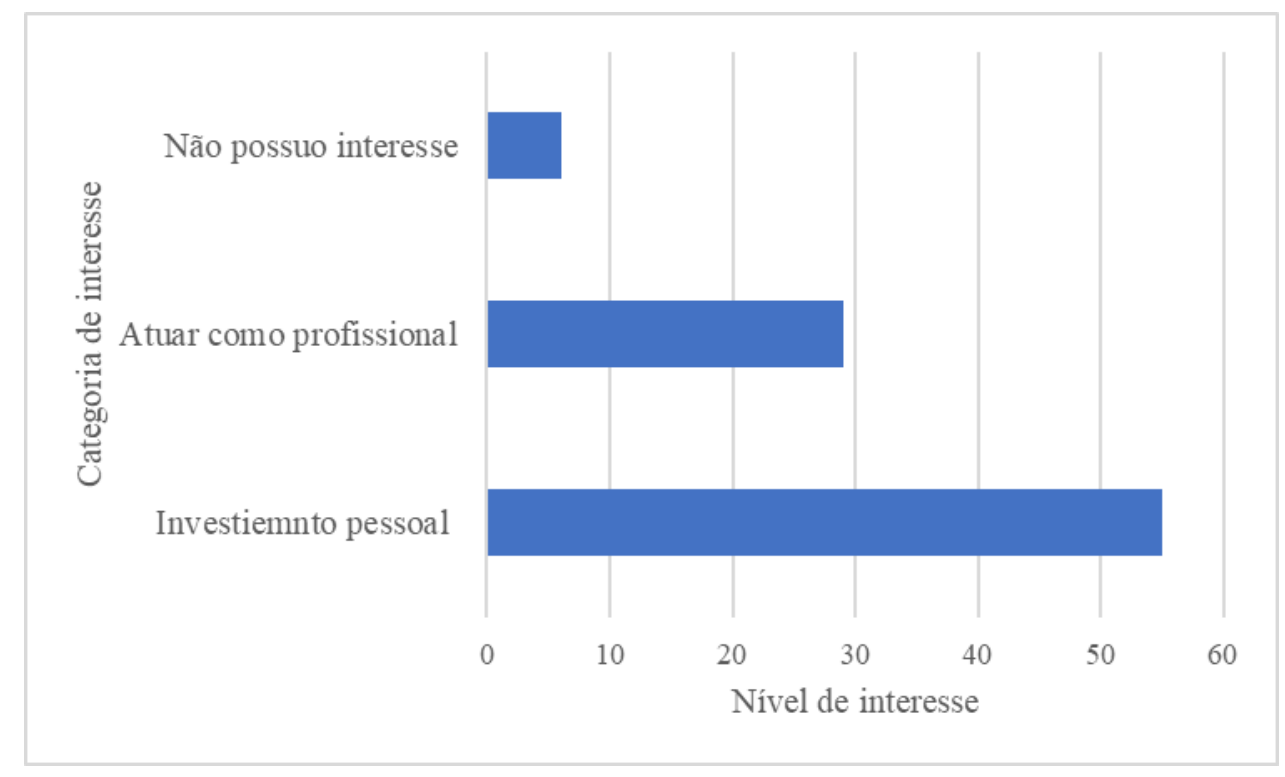

Fonte: Elaboração própria (2020)

Neste aspecto observou-se que 52\% dos alunos que possuem interesse na área financeira para investimento pessoal também desejam atuar profissionalmente no setor financeiro. Assim, corrobora-se, mais uma vez, a relevância desta área na percepção dos estudantes.

\subsection{Conhecimento no setor financeiro}

Por fim, buscou-se entender qual é o grau de conhecimento da amostra sobre o mercado financeiro mediante questionamentos sobre modalidades específicas de investimento. Os estudantes foram questionados, em escala Linkert, sobre os conhecimentos que detêm na área. Para a formulação das alternativas foi considerada a ementa das disciplinas de economia e engenharia econômica, previstas na grade de engenharia de produção UFPR. Logo, uma 
fração das respostas foi baseada em assuntos de contato na academia. Como segundo critério foram adotadas algumas das diretrizes da Certificação Profissional ANBIMA série 10 (CPA10), dada sua aplicabilidade para investimento pessoal. Cabe lembrar que 84,6\% da amostra demonstrou interesse na temática. O gráfico 6 apresenta as respostas dos estudantes sobre seu próprio conhecimento sobre carteira de investimento e fundo de investimentos, por exemplo.

Gráfico 6 - Conhecimentos gerais sobre o mercado financeiro

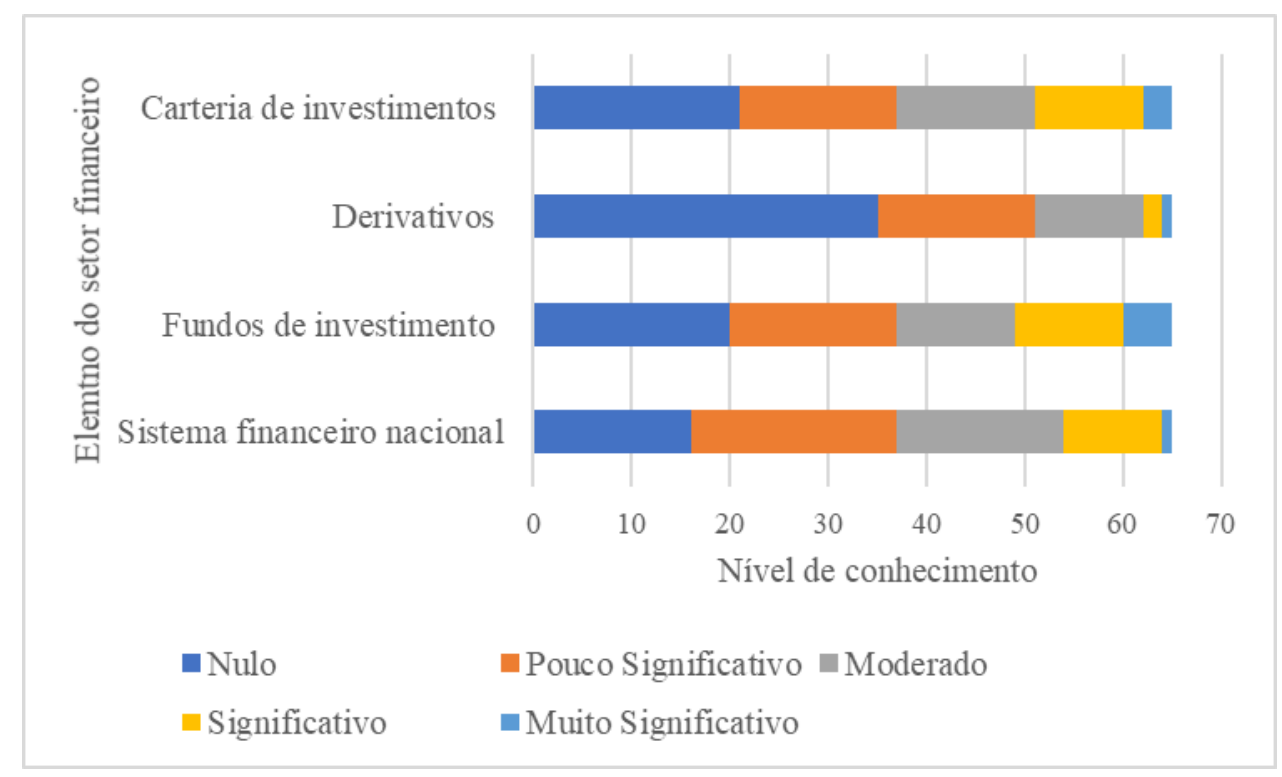

Fonte: Elaboração própria (2020)

Nota-se que "derivativos" foi o tema com a maior proporção de estudantes que declararam ter conhecimentos nulos a respeito, ainda que se trate de um tema relevante para práticas de controle de risco financeiro (hedge, por exemplo).

No que se refere à renda fixa, novamente parte importante dos estudantes declarou ter conhecimento nulo de modalidades como LF, por exemplo (gráfico 7). 
Gráfico 7 - Conhecimentos em renda fixa

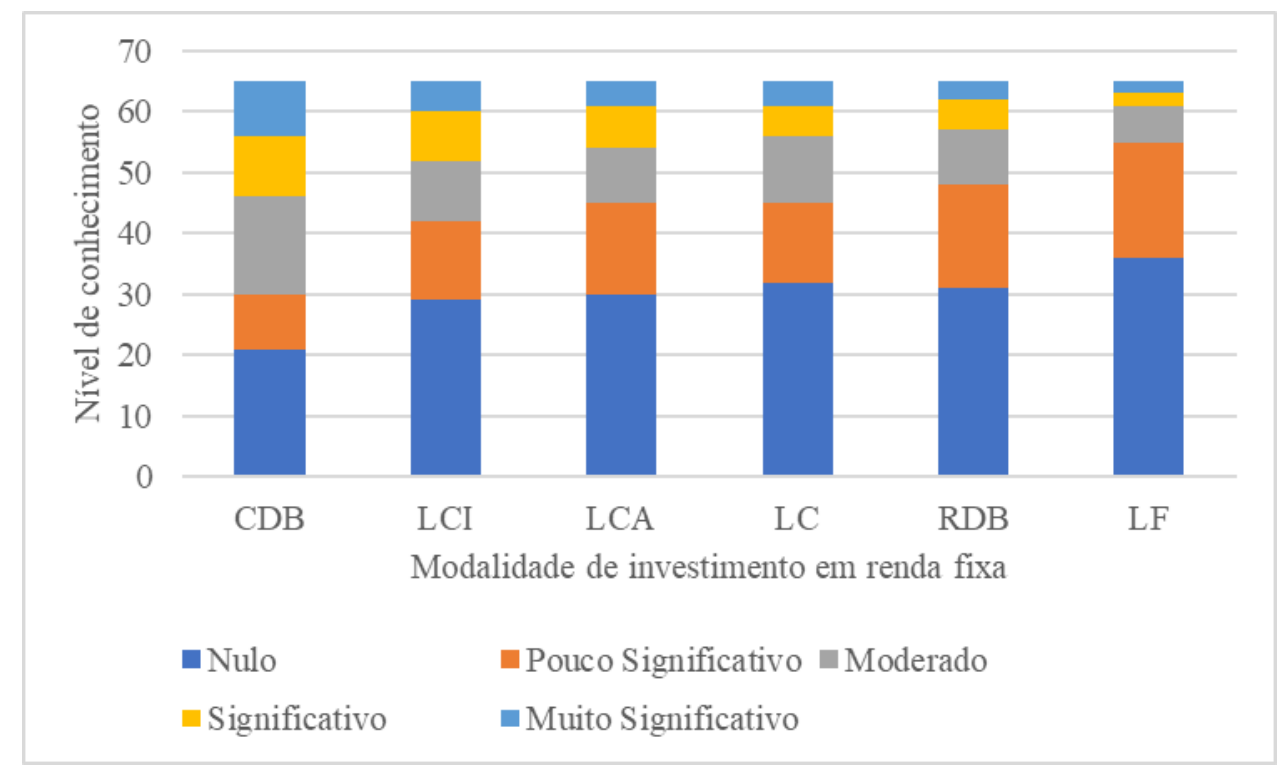

Fonte: Elaboração própria (2020)

Em termos de renda variável, as ações foram a modalidade de investimento com a menor quantidade de alunos que declararam ter conhecimento nulo a respeito. Por outro lado, robôs de investimento e COE foram as modalidades com a maior quantidade de estudantes que afirmaram não saber nada a respeito (gráfico 8).

Gráfico 8 - Conhecimentos em renda variável.

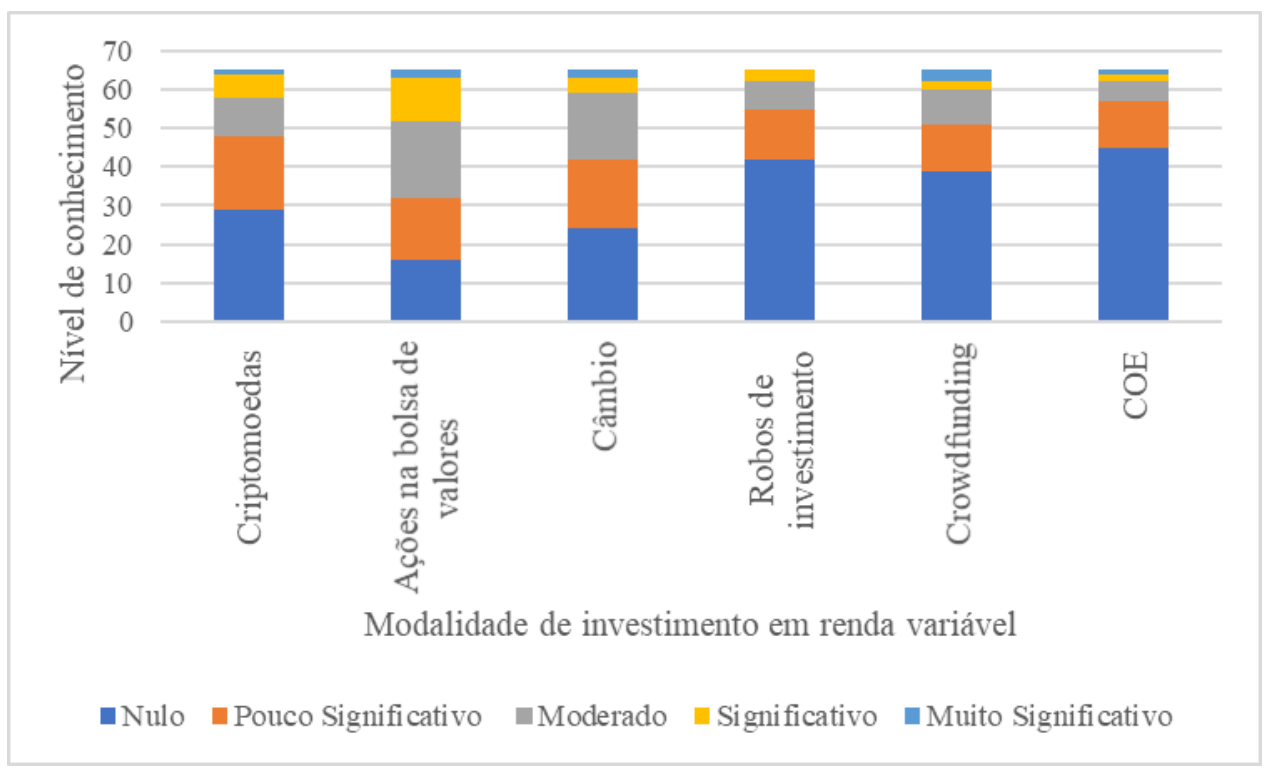

Fonte: Elaboração própria (2020)

Em termos gerais, convergindo a observação para a avaliação das alternativas relacionadas à macroeconomia e microeconomia observa-se uma maior homogeneidade no entendimento 
deste assunto, posto que $41,5 \%$ dos estudantes afirmam possuir algum ou razoável conhecimento em Sistema Financeiro. Em contrapartida, perante os investimentos de renda fixa e renda variável, os alunos apresentam maior uniformidade nas respostas apenas sobre CDB e bolsa de valores contando, ainda assim, com mais de $45 \%$ da amostra tendo conhecimento nulo ou escasso sobre o tratado.

Diante dos resultados e considerando as oportunidades profissionais disponíveis no âmbito do mercado financeiro, pode-se afirmar que há oportunidades para o aprimoramento pedagógico da formação financeira dos estudantes, seja mediante oferta de disciplinas optativas, seja mediante cursos ou workshops que acordem temas financeiros relevantes para os estudantes que pretendem atuar na área de gestão econômica.

\section{Considerações finais}

Esta pesquisa teve como objetivo identificar se o aluno de engenharia de produção apresenta interesse pessoal ou profissional no setor econômico financeiro, convergindo com as oportunidades e demanda do mercado de trabalho, visto que o mercado financeiro dispõe de inúmeras oportunidades para estes profissionais devido às suas habilidades gerenciais e de análise para tomada de decisão. Além disso, este estudo pretendeu revelar qual o nível de conhecimento dos estudantes perante temas econômicos e financeiros específicos.

A partir do levantamento, identificou-se que a maior parte dos acadêmicos que participaram da pesquisa estão inseridos no mercado de trabalho e estão cursando o $5^{\circ}$ e $9^{\circ}$ período, constatando-se assim que já cursaram disciplinas relacionadas ao setor financeiro e, também, que exercem uma avaliação mais criteriosa e realista dos questionamentos apresentados. Diante desta proposição, os dados coletados indicam que aproximadamente $45 \%$ dos discentes desejam trabalhar, de alguma forma, no mercado financeiro, enquanto outros $85 \%$ têm a pretensão de fazer investimentos pessoais num futuro próximo.

Verificou-se, ainda, que os estudantes de fato julgam que as competências financeiras são relevantes para a sua profissão. O reconhecimento da relevância, contudo, não se faz acompanhar de um conhecimento significativo sobre temas específicos da área, o que se revela uma importante oportunidade de ensino. O nível de conhecimento que os estudantes declararam ter seria inferior ao proposto pela certificação CPA 10 da ANBIMA, de modo que, para auxiliar os estudantes a se qualificarem para atuar na área, são necessárias medidas 
suplementares de ensino, seja mediante oferta de disciplinas optativas, seja mediante oferta de minicursos, oficinas ou workshops sobre temas financeiros, por exemplo.

Por fim, convém destacar que este trabalho inclui limitações, a exemplo do fato de que uma amostra maior poderia ter proporcionado resultados distintos. Outra limitação se refere ao fato de que caberia, inclusive, um detalhamento maior para as respostas apresentadas pelos estudantes. Questionários estruturados com escala Likert podem se beneficiar de entrevistas semiestruturadas para complementar a compreensão qualitativa das respostas apresentadas pelos estudantes. Compreender os motivos pelos quais determinadas repostas foram apresentadas seria relevante para promover direcionamentos pedagógicos mais adequados. Trata-se, assim, de possíveis trabalhos futuros.

\section{REFERÊNCIAS}

ANBIMA. Programa detalhado da certificação profissional ANBIMA Série 10 (CPA-10). 2019. Disponível em:

<https://www.anbima.com.br/data/files/C6/86/1E/DC/6171D6109CDE30D69B2BA2A8/K_Superintendencia\% 20Educacao_Certificacao_Certificacao_Programa\%20Detalhado_CPA-10_PD\%20CPA10_D\%2004\%2008\%2011\%20-\%20PD\%20CPA-10_versao\%206.2.pdf>. Acesso em: 02 fev. 2020.

ASSOCIAÇÃO BRASILEIRA DE ENGENHARIA DE PRODUÇÃO. Engenharia de Produção: Grande Área e Diretrizes Curriculares. 1998. Modificado em 11 de maio de 2001. Disponível em: <http://www.abepro.org.br/arquivos/websites/1/Ref_curriculares_ABEPRO.pdf>. Acesso em: 21 jan. 2020

Banco Central do Brasil. Relatório de Estabilidade Financeira, volume 18, $\mathrm{n}^{\circ}$ 2. 2019. Disponível em: <https://www.bcb.gov.br/content/publicacoes/ref/201910/RELESTAB201910-refPub.pdf>. Acesso em: 02 fev. 2020

Conselho Nacional de Educação; Câmara de Educação Superior. RESOLUÇÃO CNE/CES 11, DE 11 DE MARÇO DE 2002.2002. Disponível em: <http://portal.mec.gov.br/cne/arquivos/pdf/CES112002.pdf>. Acesso em: 21 jan. 2020.

COUTINHO, Cileda de Queiroz e Silva; SANTOS, Alan da Silva. Educação Financeira para alunos de um curso de Engenharia de Produção. Boem, Joinville, v. 4, n. 7, p.234-253, dez. 2016. Disponível em:

<http://www.revistas.udesc.br/index.php/boem/issue/view/516>. Acesso em: 01 fev. 2020.

KHALIL, Khalil Amin. A empregabilidade do engenheiro no setor econômico-financeiro: perfil psicológico, qualificação e certificação profissional ANBIMA. Fatec Zona Sul, São Paulo, v. 5, n. 3, p.1-24, fev. 2019. Disponível em: <http://www.revistarefas.com.br/index.php/RevFATECZS/article/view/257>. Acesso em: 25 jan. 2020.

MARTINS, Thais Joi; DONADONE, Julio Cesar. Realidade e desejo: as trajetórias formativas e profissionais de um grupo de elite no mundo das finanças. Estudos de Sociologia, Araraquara, v. 22, n. 43, p.263-281, dez. 2017. Disponível em: 〈https://periodicos.fclar.unesp.br/estudos/article/view/10106〉. Acesso em: 22 jan. 2020

MEDEIROS, Klara. Engenharia de Produção no mercado financeiro. EGP - Eprodução. 2018. Disponível em: <https://eproducao.eng.br/engenharia-de-producao-no-mercado-financeiro/> Acesso em: 08 fev. 2020.

PILZ, Thaísa Lana; BENEVENUTTI, Valdésio; BITTENCOURT, Evandro. Perfil e análise da ocupação profissional dos egressos de Engenharia de Produção de uma universidade do estado de Santa 
Catarina. Brazilian Applied Science Review, Curitiba, v. 2, n. 6, p.1975-1988, nov. 2018. Disponível em: <http://www.brjd.com.br/index.php/BASR/article/view/592>. Acesso em: 22 jan. 2020.

PINHEIRO, Solange Fernandes. Estruturação da área de finanças para um curso de engenharia de produção com ênfase gerencial. COBENGE, Niterói, 2001. p. 1 - 6. Disponível em:

<http://www.abenge.org.br/cobenge/arquivos/18/trabalhos/NTM011.pdf>. Acesso em: 22 jan. 2020

SILVA, Edna Lúcia da; MENEZES, Estera Muszkat. Metodologia da pesquisa e elaboração de dissertação. - 4. ed. rev. atual. - Florianópolis: UFSC, 2005. Disponível em:

<https://projetos.inf.ufsc.br/arquivos/Metodologia_de_pesquisa_e_elaboracao_de_teses_e_dissertacoes_4ed.pdf $>$ Acesso em: 20 jan. 2020

VIEIRA, Vanessa. O mercado financeiro tira os engenheiros das obras. Exame. 2013. Disponível em: <ttps://exame.abril.com.br/carreira/engenheiros-fora-de-obras/>. Acesso em: 08 fev. 2020. 